\title{
Evaluation of Point Source Pollutants impact on Water Quality and Self-purification Capacity of Abay River in Ethiopia
}

\author{
Teka Girmay Hishe ${ }^{1 *} \quad$ Dasta Brhane Asgele ${ }^{2} \quad$ Gebreyesus Brhane Tesfahunegn ${ }^{3}$ \\ Asmelash ZewduTeklehaymanot ${ }^{4}$ Eusman Ebrahim Shumey ${ }^{1}$ \\ 1.Department of Hydraulic and Water Resources Engineering, Debre Tabor University, Debre Tabor, Ethiopia \\ 2.School of Water Technology, Aksum University-Shire Campus, Shire, Ethiopia \\ 3.Department of Soil Resources and Watershed Management, College of Agriculture, Aksum University-Shire \\ Campus PO Box 314 Shire, Ethiopia \\ 4.Department of Water Supply and Environmental Engineering, Arbaminch University, Ethiopia
}

\begin{abstract}
This study was conducted to evaluate influence of point source pollutants on self-purification capacity of Abay River within $8 \mathrm{kms}$ from Lake Tana to Sebatamit. For assessment of the overall water quality level, the water quality index was used. The river's self-cleaning potential was assessed based on physicochemical parameters as indicators and using the modified Streteer-Phelps model after selecting the best reaeration coefficient through velocity and depth measurements. The outcome of the study showed that TDS, EC, BOD5, Ammonia, temperature, $\mathrm{pH}$, and salinity were found within the permissible limits of EPA. The turbidity was higher than the WHO limit at sampling point two and DO value was below the WHO and EPA limit at sampling points two, three, four, five and six. The result shows that the critical distance and time in which the river attains its self-purification capacity is at 1.3, 2.8 and $0.3 \mathrm{kms}$ from Bahirdar Textile, Bahir Dar municipal and Habesha Tannery Effluent mixing points for $1.68,0.82$ and 0.48 hour, respectively. This showed that the river have good purification capacity at a moment even though the point sources are discharging an effluent which is not properly treated.
\end{abstract}

Keywords: Physicochemical parameters, Reaeration coefficient, Water Quality Index

DOI: $10.7176 / \mathrm{CER} / 12-3-01$

Publication date:March $31^{\text {st }} 2020$

\section{INTRODUCTION}

Water contamination is caused by discharging of waste water effluent into the fresh water systems of inadequately treated sewage. This can contribute to damage to the environment of aquatic ecosystems and issues of public health(Ogundiran and Fawole, 2014).Contaminants that cause water pollution include a wide range of chemicals, bacteria, and physical changes such as high temperatures (Ogundiran and Fawole, 2014). More than half of the world's major rivers are degraded, according to the world water commission for the 21 st century. They are therefore threatening human health and destroying the habitats around them (Nyasulu, 2012). Diseases such as typhoid fever, cholera and other intestinal diseases are caused due to drinking of contaminated water (Danquah, 2010).

Waste disposal and management are major challenges, which confront urban centers throughout the world. The habit of untreated sewage discharges into surface water bodies is popular in many developing countries. This is due to the expansion of industrialization and high urbanized societies with lack of waste management facilities. In Ethiopia, the wastewater effluents from different sources are joining the river without and partially treatment. In Addis Abeba, Ethiopia 40 percent of streams are contaminated by various wastewater discharges into rivers(Yohannes and Elias, 2017), (Beyene et al., 2009).Abay River is one of the water bodies in Ethiopia which is affected by discharge of untreated effluent. Bahir Dar textile, Habesha Tannery and Bahir Dar Tannery discharge their effluents without treatment and with partially treatment directly into the Abay River which is the source of Blue Nile River.

Many studies conducted in different parts of the world showed a considerable river water quality change due to point sources(Van der Hoven et al., 2017). Abrehet et al have reported that the pollution of the water body by textile industry effluents discharged into the stream such as the textile industry effluent showed considerable negative effects on the water quality of the streams and human health(Mehari et al., 2015). Assefa Wosenie et al stated that effluents from tannery highly affect the micro invertebrates and industrial effluents and toxic substances that have a number of adverse effects on the water bodies. The level of damage at the downstream intermediate site was high and at the upstream site it was very little. This high downstream weakness made water undesirable for domestic, agricultural and esthetic uses(Mehari et al., 2015).

Natural water systems self-purification is a difficult process that often requires simultaneous physical, chemical and biological processes. The water is purified in the sense that the concentration of waste materials has been reduced mostly by means of biodegradation processes. Therefore, this process is very closely tied with the dissolved oxygen content and all the sources and sinks of oxygen in a river(Taseiko et al.). Several problems have arisen because of the reduction in the self-cleaning capacity of streams. Dissolved oxygen (DO) is one of the vital for microorganisms in water bodies and is an important indicator of the aquatic ecosystem's health. A particular 
ecosystem DO can differ as a function of many interlinked dynamic parameters such as, the presence of organic contaminants and marine species biological activities. It is therefore important and timely to apply models that can effectively predict the DO of a river water influenced by contamination from the point source(Omole and Longe, 2008).

The Abay River, which is source of the Blue Nile River, is the main surface water supply for over 20 million people in Ethiopia, and over 300 million societies at downstream part of the Nile Stream (Yitayew and Melesse, 2011). There have been several efforts to improve the reliability of river water and attempts to drain wastewater treatment plants from point source. Such efforts by wastewater treatment plants and industrial wastewater treatment plants, however, are not yet fully implemented and operated in the River Basin, where point sources can be a major cause of contamination for Abay River. The overall objective of this analysis was to evaluate point source pollutants impact on Abay River water self-cleaning potential at the head of the Blue Nile River (Abay River in Ethiopia). The specific goals were to identify the influence of pollution sources on Abay River's quality of water and to measure the Abay River's pollution status using the water quality index. This was selected because of water quality index model simplifies and show water quality statues in short way (Bora and Goswami, 2017; Dutta et al., 2018; Elshemy and Meon, 2016).

\section{MATERIALS AND METHODS}

\subsection{Description of Study area}

Abay River is situated in Ethiopia's National Regional State of Amhara. The study area is located on the southern shore of the heart-shaped Tana Lake (Figure 1), the source of the river Blue Nile, around $565 \mathrm{~km}$ northwest of Addis Ababa. It has $1801 \mathrm{~m}$ above sea level and $11^{0} 38^{\prime} \mathrm{N}$ latitude and $37^{\circ} 1^{\prime} \mathrm{E}$ longitude. The Nile basin comprises more than 10 percent of the landmass of Africa in more than 11 countries including Ethiopia, Sudan and Egypt. Almost all those countries water source is depend on Nile River. Except 20 percent of amount of water of Egypt, the remain is contributing from Ethiopian highlands (Conniff et al., 2013).

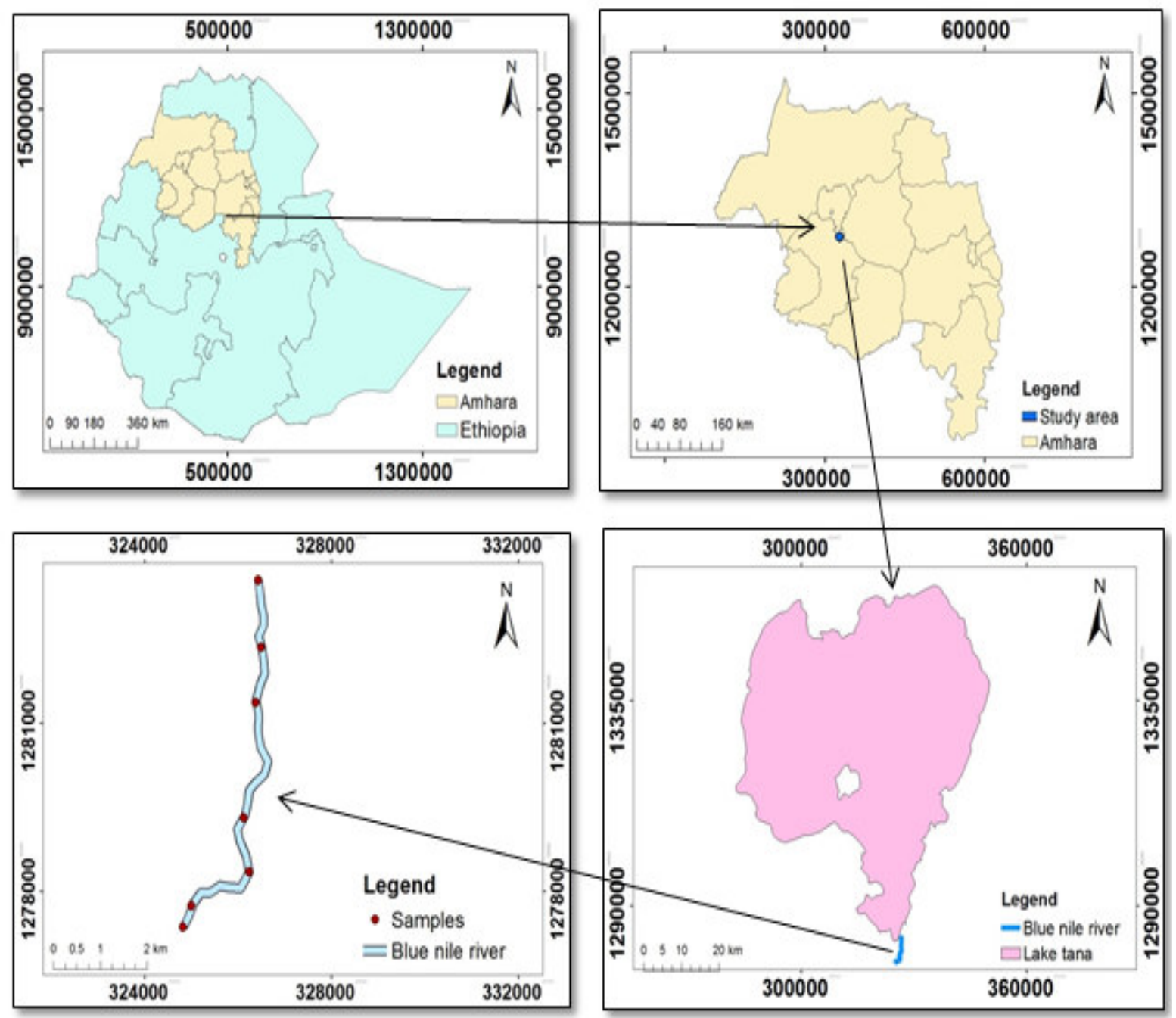

Figure 1 showed that a) Ethiopia, b) Amhara Regional State, c) Tena Lake and d) Abay River (Blue Nile) 
Table 1location and relative distances of sampling points

\begin{tabular}{|c|c|c|c|c|c|}
\hline SP & $\begin{array}{c}\text { Relative } \\
\text { Distance } \\
(\mathrm{km})\end{array}$ & $\mathrm{X}$ & $\mathrm{Y}$ & $\mathrm{Z}$ & Description \\
\hline SP1 & 0 & $11036 ' 24.07 "$ & $37 \mathrm{o} 24^{\prime} 28.37^{\prime \prime}$ & 1795 & $\begin{array}{c}\text { Upstream site after } \\
\text { River Abay leave Lake Tana. }\end{array}$ \\
\hline SP2 & 1.3 & $11^{\circ} 35^{\prime} 45.09^{\prime \prime}$ & $37024 ' 30.90^{\prime \prime}$ & 1799 & $\begin{array}{l}\text { Textile effluent } \\
\text { Mixed with Abay River. }\end{array}$ \\
\hline SP3 & 2.3 & $11^{\circ} 35^{\prime} 12.93^{\prime \prime}$ & $37 \mathrm{o} 24^{\prime} 27.2^{\prime \prime}$ & 1790 & Between textile and ditch \\
\hline SP4 & 4.8 & $11^{\circ} 34^{\prime} 6.66^{\prime \prime}$ & $37 \mathrm{o} 24^{\prime} 18.53^{\prime \prime}$ & 1799 & $\begin{array}{l}\text { Municipal ditch } \\
\text { mixed with Abay River }\end{array}$ \\
\hline SP5 & 7.6 & $11^{\circ} 33^{\prime} 15.04^{\prime \prime}$ & $37 \mathrm{o} 23^{\prime} 42.48^{\prime \prime}$ & 1791 & $\begin{array}{l}\text { Around Bahir dar tannery } \\
\text { effluent mix with Abay River }\end{array}$ \\
\hline SP6 & 7.85 & $11^{\circ} 33^{\prime} 3.17^{\prime \prime}$ & $37 \mathrm{o} 23^{\prime} 35.78^{\prime \prime}$ & 1789 & $\begin{array}{l}\text { Habesha tannery effluent } \\
\text { mixed with Abay river }\end{array}$ \\
\hline SP7 & 8 & $11^{\circ} 33^{\prime} 2.75^{\prime \prime}$ & $37 \mathrm{o} 23^{\prime} 36.66^{\prime \prime}$ & 1789 & $\begin{array}{l}\text { The most downstream } \\
\text { Of sampling sites. }\end{array}$ \\
\hline $\begin{array}{l}\text { E1 } \\
\text { E2 }\end{array}$ & & $\begin{array}{l}11^{\circ} 35^{\prime} 43.13^{\prime \prime} \\
11^{\circ} 34^{\prime} 7.25^{\prime \prime}\end{array}$ & $\begin{array}{l}37^{\circ} 24^{\prime} 24.18^{\prime \prime} \\
37^{\circ} 24^{\prime} 17.87^{\prime \prime}\end{array}$ & & $\begin{array}{c}\text { Bahir Dar textile effluent } \\
\text { Bahir Dar municipal ditch effluent }\end{array}$ \\
\hline E3 & & $11^{\circ} 33^{\prime} 5.24^{\prime \prime}$ & $37^{\circ} 23^{\prime} 31.81^{\prime \prime}$ & & Habesha tannery effluent \\
\hline
\end{tabular}

\subsection{Selection of Water and wastewater sampling points}

The samples were collected from 10 sampling sites including 3 point sources for wastewater effluent discharge labeled (E1 to E3) and 7 sampling sites (SP1 to SP7) along the segment of the river before and after effluent mixing. The three point sources (E1 to E3) were from Bahir Dar textile effluent, Bahir Dar municipal effluent and Habesha Tannery effluent, respectively.

\subsection{Sample collection and Water Quality parameters}

From each sampling point 3 wastewater samples were collected at a 3 points along the wididith (edge, center, and edge) 3 times. Samples were taken from 3 sections of the stream to minimize inaccuracies that can be made during data collection and also samples were taken at a depth of about $20 \mathrm{~cm}$ just under the water surface(Ibrahim et al., 2019; Shrivastava et al., 2015). Measurements of physico-chemical water quality parameters from the samples were carried out using laboratory analyzes in accordance with the procedures for standard water and wastewater testing methods described for water quality analysis(Shrivastava et al., 2015). The parameters such as BOD (Biological Oxygen Demand) and Turbidity were assessed in the laboratory of the Bahir Dar University Institute of Technology, Bahir Dar University. At Amhara Design and Supervision Work Enterprise Laboratory, ammonia - nitrogen $\left(\mathrm{NH}_{3}-\mathrm{N}\right.$ ) was measured. Temperature, $\mathrm{PH}, \mathrm{EC}$ (electrical conductivity), DO (dissolved oxygen), TDS (total dissolved solids), and salinity were also measured using the field meter YSI 556 Multi Prob (FernándezGómez et al., 2012).

\subsection{Assessment of the water quality using Water Quality Index (WQI)}

Water quality index is a model used to quantify the general quality status of particular sampling station taken from lakes and rivers [13]. Essentially, the WQI is a compilation of a number of parameters which could be used to determine the overall quality of the river (Jahin et al., 2019). The Water Quality Index value can be found by multiplying Xr value and the unit weight (Wi).WQI= Wi x Xr. Kumar et al, 2012 was used Xr value based on the scale of different water quality parameters as shown in Tables 1 below (Balan et al., 2012). 
Table 2 Rating Scale for Calculation of WQI (Sources: (Kumar et al, 2012))

\begin{tabular}{cccccc}
\hline & \multicolumn{5}{c}{ Ranges } \\
pH & $7.0-8.5$ & $8.6-8.7$ & $8.8-8.9$ & $9.0-9.2$ & $>9$ \\
DO & $>7.0$ & $6.8-6.9$ & $6.7-6.8$ & $6.5-6.7$ & $<6.5$ \\
EC & $0-75$ & $75.1-150$ & $150.1-225$ & $225.1-300$ & $>300$ \\
TDS & $0-375$ & $375.1-750$ & $750.1-1125$ & $1125.1-1500$ & $>1500$ \\
\hline Xr & 100 & 80 & 60 & 40 & 0 \\
\hline \multirow{2}{*}{ Pollution status } & \multirow{2}{*}{ Clean } & Slightly & Medium & Excess & Severe \\
& & Pollution & Pollution & pollution & pollution \\
\hline
\end{tabular}

DO (Dissolved Oxygen), EC (electrical conductivity) and TDS (total dissolved solids)

Water quality status of river can be classified as excellent to bad based on water quality index. According to Kumar et al, 2012 the water quality status can classified based on water quality index values as excellent ( 90 100), good (70-90), medium(50-70) and bad (25-50) (Balan et al., 2012).

\subsection{Methods used for Self-purification of Abay River \\ 2.5.1 Selection of Reaeration Coefficient Models}

According to Lazorchak, J.M., Klemm, D.J., Peck, D.V. (1999) in order to select the best appropriate reaeration coefficient average velocity and depth should be taken between 20 intervals (Nel, 2008). Based on this the average velocity and depth were measured at 25 points along the river width for each sampling points except SP4 due to its high depth. At each sampling points, velocity and depth were measured using current meter. The river crosssection was determined by tape across its width and the stream discharge was calculated using the method of Velocity-Area. Using Handheld GPS unit and Google Earth Pro, the overall segment distance and the geographic position of each sampling point was collected. The performance of the model was evaluated by inserting the Ka value and the amount of dissolved oxygen (DO) predicted. The observed and simulated data was used to check the performance of the model. To select the appropriate Ka values different Ka values was tried by inserting on the DO model (Hill et al., 2003).

$D=D_{0} e^{-K_{a} t}+\frac{K_{d} L_{o}}{K_{a}-K_{r}}\left(e^{-K_{r} t}-e^{-K_{a} t}\right)+\frac{K_{n} L_{n o}}{K_{a}-K_{n}}\left(e^{-K_{n} t}-e^{-K_{a} t}\right)+\frac{S}{k_{a} H}\left(1-e^{-k_{a} x / u}\right)+\frac{R-P}{K_{a}}\left(1-e^{-K_{a} x / u}\right)$

Equation 1

All bathymetric data gathered by travelling by boat and on foot were entered into an equation1. The best fitted reaeration coefficient $(\mathrm{Ka})$ was selected by comparing the results found by inserting Ka values of Street-Phleps, Agummba, O'Connor and Dobbins in equation 1. For this particular place Street-Phleps reaeration coefficient was used in the study area because of its successful prediction of DO value. The re-aeration coefficient proposed by Streeter et al (Streeter et al., 1936) was defined as:

$\mathbf{k}_{\mathbf{a}}=\mathbf{5 . 0 2 6} \frac{\mathbf{U}^{\mathbf{0 . 9 6 9}}}{\mathbf{H}^{\mathbf{1 . 6 7 3}}} \quad$ Equation 2

Agunwamba et al. (2007), working on the Amadi Creek, proposed a ka defined as(Agunwamba et al., 2006):

$\mathbf{k}_{\mathbf{a}}=\mathbf{1 1 . 6 3 2 5} \frac{\mathbf{U}^{\mathbf{1 . 0 9 5 4}}}{\mathbf{H}^{\mathbf{0 . 0 0 1 6}}} \quad$ Equation 3

O’Connor and Dobbins, 1958(O'Connor and Dobbins, 1958)

$\mathbf{k}_{\mathrm{a}}=3.9 \frac{\mathrm{U}^{0.5}}{\mathrm{H}^{1.5}}$

Equation 4

For all equations 2, 3 and 4; $\mathrm{U}$ (average velocity in $\mathrm{m} / \mathrm{s}$ ) and $\mathrm{H}$ (Average Depth in $\mathrm{m}$ ) and those values were measured by the help of current meter.

The performance of the model was evaluated by inserting the Ka value and the amount of dissolved oxygen (DO) was predicted. The observed and simulated data was used to check the performance of the model. To select the appropriate Ka values different Ka values was tried by inserting on the DO model.

\subsubsection{Determination of the oxygen deficit and critical time}

To evaluate self-purification capacity modified Streteer-Phelps model were used. To get the distance where can be the river attain its self-purification capacity and the critical dissolved oxygen values equation 5 and 6 were proposed by Gotovtsev et al (Gotovtsev, 2010).

$$
\begin{array}{ll}
\mathbf{t}_{\mathbf{c}}=\frac{1}{\mathbf{k}_{\mathbf{a}}-\mathbf{k r}} \ln \left[\frac{\mathbf{k}_{\mathbf{a}}}{\mathbf{k}_{\mathbf{r}}}\left(1-\left(\frac{\mathbf{D}_{\mathbf{o}}}{\mathbf{k}_{\mathbf{d}} \mathbf{L}_{\mathbf{o}}}\left(\mathbf{k}_{\mathbf{a}}-\mathbf{k}_{\mathbf{r}}\right)\right)\right]\right. & \text { Equation 5 } \\
\mathbf{D}_{\mathbf{c}}=\frac{\boldsymbol{k}_{r} \mathbf{L}_{\mathbf{o}}}{\mathbf{k}_{\mathbf{a}}}\left[\frac{\mathbf{k}_{\mathbf{a}}}{\mathbf{k}_{\mathbf{r}}}\left(1-\frac{\mathbf{D}_{\mathbf{o}}}{\mathbf{L}_{\mathbf{o}}}\left(\frac{\mathbf{k}_{\mathbf{a}}-\mathbf{k}_{\mathbf{r}}}{\mathbf{k}_{\mathbf{a}}}\right)\right)\right]^{-\frac{\mathbf{k}_{\mathbf{r}}}{\mathbf{k}_{\mathbf{a}}-\mathbf{k}_{\mathbf{r}}}} & \text { Equation 6 }
\end{array}
$$

The saturation dissolved oxygen is dependent on temperature and was calculated as follows: 
$S_{s}=14.652-0.41022 T+0.007991 T^{2}-0.000077774 T^{3}$

Equation 7

Equation 7 gives the concentration Ss (expressed in $\mathrm{g} / \mathrm{m}^{3}$ ) as function of the temperature in ${ }^{\circ} \mathrm{C}$.

\section{RESULT AND DISCUSSION}

3.1 Results of different Water quality parameters

Table 3Water quality Results obtained during data collection (Average $\pm \mathrm{SD}$ )

\begin{tabular}{llccc}
\hline Sampling Points & Temperature $\left({ }^{\circ}\right)(\mathrm{n}=2)$ & $\begin{array}{c}\mathrm{EC}(\mu \mathrm{S} / \mathrm{cm}) \\
(\mathrm{n}=2)\end{array}$ & $\begin{array}{c}\mathrm{TDS}(\mathrm{mg} / \mathrm{L}) \\
(\mathrm{n}=2)\end{array}$ & $\begin{array}{c}\mathrm{pH} \\
(\mathrm{n}=2)\end{array}$ \\
\hline SP1 & $23.53 \pm 0.34$ & $203.0 \pm 3.7$ & $131.98 \pm 47.53$ & $7.23 \pm 0.58$ \\
SP2 & $25.0 \pm 2.3$ & $203.3 \pm 53.4$ & $132.13 \pm 34.36$ & $7.69 \pm 0.37$ \\
SP3 & $24.1 \pm 1.66$ & $197.1 \pm 68.99$ & $128.13 \pm 41.48$ & $7.08 \pm 0.35$ \\
SP4 & $24.72 \pm 1.2$ & $188.6 \pm 60.74$ & $122.61 \pm 30.39$ & $7.06 \pm 0.39$ \\
SP5 & $24.76 \pm 0.42$ & $202.6 \pm 51.07$ & $131.7 \pm 34.45$ & $7.29 \pm 0.83$ \\
SP6 & $25.72 \pm 1.2$ & $203.5 \pm 51.08$ & $132.26 \pm 33.65$ & $7.28 \pm 0.73$ \\
SP7 & $24.54 \pm 0.42$ & $201.6 \pm 55.48$ & $131.07 \pm 35.88$ & $6.96 \pm 0.27$ \\
\hline
\end{tabular}

Table 4 Water quality Results obtained during data collection (Average $\pm \mathrm{SD}$ )

\begin{tabular}{llllcc}
\hline Sampling Points & Turbidity(NTU) & DO(mg/L) & BOD $(\mathrm{mg} / \mathrm{L})$ & Ammonia $(\mathrm{mg} / \mathrm{L})$ & Salinity \\
\hline SP1 & $20.62 \pm 17.22$ & $6.5 \pm 0.3$ & $25 \pm 3.5$ & 0.13 & 0.1 \\
SP2 & $31.23 \pm 8.07$ & $3.37 \pm 0.18$ & $30 \pm 1.4$ & 0.06 & 0.1 \\
SP3 & $20.39 \pm 6.94$ & $3.91 \pm 0.15$ & $23 \pm 2.1$ & 0.03 & 0.1 \\
SP4 & $17.2 \pm 2.18$ & $2.85 \pm 0.32$ & $40 \pm 7.1$ & 0.02 & 0.1 \\
SP5 & $12.72 \pm 2.83$ & $4.2 \pm 0.06$ & $27 \pm 3.5$ & 0.26 & 0.1 \\
SP6 & $14.75 \pm 2.72$ & $3.3 \pm 0.10$ & $38 \pm 5.6$ & 0.18 & 0.1 \\
SP7 & $10.45 \pm 3.16$ & $5.0 \pm 0.03$ & $15.5 \pm 0.71$ & 0.04 & 0.1 \\
\hline
\end{tabular}

Table 5 Effluent quality

\begin{tabular}{cccccccc}
\hline NO. & $\mathrm{pH}$ & $\begin{array}{c}\text { Temperature } \\
\left({ }^{\circ} \mathrm{C}\right)\end{array}$ & $\begin{array}{c}\mathrm{TDS} \\
(\mathrm{mg} / \mathrm{L})\end{array}$ & $\mathrm{EC}(\mu \mathrm{S} / \mathrm{cm})$ & Salinity & $\begin{array}{c}\mathrm{BOD}_{5} \\
(\mathrm{mg} / \mathrm{L})\end{array}$ & $\mathrm{DO}(\mathrm{mg} / \mathrm{L})$ \\
\hline E1 & $8.4 \pm 0.8$ & $21.8 \pm 1.7$ & $370 \pm 36.8$ & $569 \pm 56.6$ & 0.11 & $36 \pm 1.4$ & $3.8 \pm 0.6$ \\
$\mathrm{E} 2$ & $6.7 \pm 0.1$ & $19.8 \pm 1.7$ & $604.6 \pm 77.1$ & $930 \pm 118.7$ & 0.65 & $27 \pm 4.2$ & $3.7 \pm 0.2$ \\
$\mathrm{E} 3$ & $7.6 \pm 0.6$ & $21 \pm 1.4$ & $2300 \pm 148.5$ & $3538.5 \pm 228.4$ & 2.5 & $70 \pm 14$ & $3.3 \pm 0.1$ \\
\hline
\end{tabular}

The different water quality parameters tested and evaluated based on standards was presented in table 3,4 and $5 . \mathrm{BOD}_{5}(\mathrm{mg} / \mathrm{L})$ and $\mathrm{DO}(\mathrm{mg} / \mathrm{L})$ from Habesha Tannery were above the permissible limit of WHO and EPA, whereas $\mathrm{pH}$, temperature and $\mathrm{BOD}_{5}$ from textile and municipal ditch were within the permissible limit of EPA and WHO for surface water course. Except effluent concentration from textile factory, the amount of total dissolved solids $(\mathrm{mg} / \mathrm{L})$ from Habesha tannery and municipal ditch was higher than the allowable limit of $500 \mathrm{mg} / \mathrm{L}$. But the amount of electrical conductivity showed that all point sources effluent contains higher than the allowable limit of WHO (300) for surface water. The $\mathrm{NH}_{3}-\mathrm{N}$ values for all surface water sampling stations were lower than the WHO standard of $30 \mathrm{mg} / \mathrm{L}$ and the EPA limit of $20 \mathrm{mg} / 1$ for surface water(Shrivastava et al., 2015). The amount of ammonia concentration was high at SP5. It can conclude that the tanneries and animal activities increase the amount of ammonia concentration in this sampling point. Generally, the concentration of ammonia at all sampling points was within a permissible limit of EPA $(<20 \mathrm{mg} / \mathrm{l})$ for surface water(Paul, 2011). Except at the sampling point of SP2 the turbidity of all sampling sites were within WHO guide line for surface water (30 mg/L) (Falkowski et al., 1980). The turbidity at SP2 was due to car washing and textile wastewater effluent join the river around that place. At the time of sampling, the mean water temperature was $24.5{ }^{\circ} \mathrm{C}$ which is within the WHO and EPA standard. Sampling points SP2and SP6 recording the relatively higher temperature due to the entry of waste water effluent from Bahir Dar Textile Factory and Habesha Tannery effluent.

The river water exhibited a near neutral $\mathrm{pH}$ (7.06-7.96) and this value found within the interval of WHO and EPA (6.5-9) for drinking water. Awomeso, J., et al (2010) showed that when the pH value is within the WHO interval, micro-organisms that help break down biological waste could stay alive in such a neutral environment and can easily degrade the biological waste water entering the river(Orebiyi et al., 2010). The conductivity apparently increased at sampling stations SP2 $(203.3 \mu \mathrm{S} / \mathrm{cm})$, SP5 $(202.61 \mu \mathrm{S} / \mathrm{cm})$ and SP6 $(203.48 \mu \mathrm{S} / \mathrm{cm})$, respectively due to Textile industry and Habesha Tannery wastewaters effluent. The values of electrical conductivity from the point sources were above permissible limit defended by WHO and EPA. However, this value on the river was within the permissible limit of surface water course of $300 \mu \mathrm{S} / \mathrm{cm}$. The TDS content of water samples obtained at selected stations ranged from $122,61 \mathrm{mg} / \mathrm{L}$ to $132,26 \mathrm{mg} /$ that were below the 
WHO maximum standard value of $500 \mathrm{mg} / \mathrm{L}$ (Paul, 2011).Increasing TDS and conductivity showed that the water is contaminated by domestic and industrial sewage discharges.

The amount of BOD concentration at sampling points SP2, SP4 and SP6 was high (Table 4). This showed that Textile factory at SP2, Municipal wastewater at SP4 and Habesha Tannery factory at SP6 have adverse impact on the river water pollution. Especially municipal wastewater ditch covers several parts of the town and collected different wastewater that can be affected water quality. All sampling station contains the amount of BOD above permissible limit defined by WHO and EEPA for river discharge $(<40-50 \mathrm{mg} / \mathrm{L})$. Except the DO values of SP1 and SP7, DO value of Abay River was found below the desired value $(5 \mathrm{mg} / \mathrm{L})$ as per the WHO guidelines for surface water courses. In SP2, SP4, and SP6 sample stations, the lowest DO values were observed. As it could have observed when water moves steadily away from upstream (SP1) there were successive changes in pollution. As a result, the river's self-purification could disrupt the predicted usual spoon-shaped DO curve in several places along the stream.

\subsection{Water Quality index}

The results of the WQI for the sampling points showed that the water quality of the Abay River is impaired by the point sources of pollution, except for the sampling points SP1 upstream point and SP7 the most downstream portion. According to the water quality index-sampling site SP2, SP3, SP5 and SP6 were ranked as a medium polluted sites due to Bahir Dar Tannery and Habesha Tannery effluents entered at SP5 and SP6. Due to the wastewater effluents from Bahir Dar Municipal, sampling site SP4 was badly polluted site. The Weighted factor for different parameters as shown on table 6 was calculated based on Akkaraboyina et al, 2012 (Akkaraboyina and Raju, 2012).

Table 6 Weight factor of different parameters

\begin{tabular}{cccc}
\hline Parameters & $\begin{array}{c}\text { Permissible Limit(Xi) } \\
\text { (WHO for surface water) }\end{array}$ & $1 / \mathrm{Xi}$ & $\mathrm{Wi}=(\mathrm{k} / \mathrm{Xi})$ \\
\hline $\mathrm{pH}$ & 9 & 0.111 & 0.35 \\
$\mathrm{DO}$ & 5 & 0.2 & 0.63 \\
$\mathrm{EC}$ & 300 & 0.003 & 0.01 \\
TDS & 500 & 0.002 & 0.01 \\
\hline
\end{tabular}

Where, $\mathrm{k}=\frac{1}{\sum_{\mathrm{i}=1}^{\mathrm{n}}\left(\frac{1}{\mathrm{x}_{i}}\right)}=\frac{1}{\sum_{\mathrm{i}=1}^{4} 0.316}=3.164$

Table 7 Water quality index of sampling points of Abay River

\begin{tabular}{lccccccc}
\hline WQI & Sp1 & \multicolumn{1}{c}{ Sp2 } & Sp3 & Sp4 & Sp5 & Sp6 & Sp7 \\
\hline Xr(pH) & 100 & 100 & 100 & 100 & 100 & 100 & 100 \\
Xr(DO) & 80 & 40 & 40 & 0 & 40 & 40 & 80 \\
Xr(EC) & 60 & 60 & 60 & 60 & 60 & 60 & 60 \\
Xr(TDS) & 100 & 100 & 100 & 100 & 100 & 100 & 100 \\
Wi(pH) & 0.351 & 0.351 & 0.351 & 0.351 & 0.351 & 0.351 & 0.351 \\
Wi(DO) & 0.632 & 0.632 & 0.632 & 0.632 & 0.632 & 0.632 & 0.632 \\
Wi(EC) & 0.01 & 0.01 & 0.01 & 0.01 & 0.01 & 0.01 & 0.01 \\
Wi(TDS) & 0.0063 & 0.0063 & 0.0063 & 0.0063 & 0.0063 & 0.0063 & 0.0063 \\
\hline WQI = $\sum$ (Wi*Xr) & 86.89 & 61.61 & 61.61 & 36.33 & 61.61 & 61.61 & 86.89 \\
Water quality status & Good & Medium & Medium & Bad & Medium & Medium & Good \\
\hline
\end{tabular}

\subsection{Reaeration Coefficient Modeling}

O'Connor and Dobbins was predicted DO values about $80.24 \%$, Streeter-Phelps predicts $82.62 \%$ and Agunwamba et al predicts about $71.4 \%$. Therefore, the best reaeration coefficient that predicts the amount of dissolved oxygen for the river was using Streeter - Phelps reaeration coefficient model.

\subsection{Self-Purification Capacity}

The minimum amount of dissolved oxygen was observed around the point sources and value was gradually increased when away from the point sources. The concentrations of pollutants from the point sources were above the permissible limit defined by world health organization. But except some parameters like BOD the pollutants which join to the river they dispersed, diluted and found within the acceptable level.

\section{CONCLUSION}

The pollutants effluent concentration generated from point sources were above permissible limit of World health 
organization. The amount of dissolved oxygen that showed to as self-purification capacity was below the recommended limit of World health organization of $4 \mathrm{mg} / \mathrm{L}$ at all the mixing point of point sources with stream. Similar to that water quality index results all sampling points except sampling points one and seven the rest sampling points showed that the river is affected by the point sources. According to Streeter-Phelps model prediction the effluent from Bahir Dar textile, Habesha Tannery and Bahir Dar municipal was purified by the river. When it is tray to evaluate the point sources the segment of the river were divide in to three reaches based on the location of those point sources. Reaches 1 was include SP1, SP2 and SP3, reach2 includes SP4and SP5 and reach3 includes SP6 and SP7. The Streeter-phleps model predicted self-purification of the river distance from the source at reach one to be $1.3 \mathrm{~km}$ from Bahir Dar Textile mixing point at $1.68 \mathrm{hr}$. The observed oxygen also showed at this reach the river attained its self-purification capacity. At reach2 the self-purification capacity was expected to be at $2.8 \mathrm{~km}$ from Bahir Dar municipal wastewater effluent mixing point at $0.82 \mathrm{hr}$. In the final reach reach3, the self-purification capacity was predicted at $0.3 \mathrm{k} \mathrm{m}$ after mixing of Habesha Tannery effluent to the river flow at $0.48 \mathrm{hr}$. The amount of oxygen found in reach 2 was very lower than the other reaches. This showed that the municipal wastewater effluent highly affect the river water quality and interrupting the self-purification capacity. It can be concluded from the findings that the river currently has a good capacity for self-purification, even though the point sources discharge an effluent that is not properly treated and interrupt the river's capacity for selfpurification. If water pollution is not properly monitored, the scale of pollutants from point sources will increase in the future.

\section{Acknowledgment}

Our special thanks to the advisor, Dr. Beshah Mogessie, for his precious and valuable guidance, encouragement and decisive comment from the inception to the completion of this research work. We want to express our thanks to Mr. Eshetu Assefa water supply and sanitary chairperson at Bahir Dar University for his sincere commitment, supervision and frequent encouragement during the progress of the research. We gratefully acknowledge the following organizations for supported us materials such as Hydraulic and Water Resources department, Bahirdar University and Blue Nile Water institute. The last, but not the least, we would like to thank all our friends who supported us during data collection.

\section{REFERENCES}

Agunwamba, J., Maduka, C., Ofosaren, A. (2006) Analysis of pollution status of Amadi Creek and its management. Journal of Water Supply: Research and Technology-AQUA 55, 427-435.

Akkaraboyina, M.K., Raju, B. (2012) A comparative study of water quality indices of river godavari. International Journal of Engineering Research and Development 2, 29-34.

Balan, I.N., Shivakumar, M., Kumar, P.M. (2012) An assessment of groundwater quality using water quality index in Chennai, Tamil Nadu, India. Chronicles of Young Scientists 3, 146.

Beyene, A., Addis, T., Kifle, D., Legesse, W., Kloos, H., Triest, L. (2009) Comparative study of diatoms and macroinvertebrates as indicators of severe water pollution: case study of the Kebena and Akaki rivers in Addis Ababa, Ethiopia. ecological indicators 9, 381-392.

Bora, M., Goswami, D.C. (2017) Water quality assessment in terms of water quality index (WQI): case study of the Kolong River, Assam, India. Applied Water Science 7, 3125-3135.

Conniff, K., Molden, D., Peden, D., Awulachew, S.B., (2013) Nile water and agriculture: Past, present and future, The Nile River Basin. Routledge, pp. 27-51.

Danquah, L., (2010) The causes and health effects of river pollution: a case study of the Aboabo River, Kumasi.

Dutta, S., Dwivedi, A., Kumar, M.S. (2018) Use of water quality index and multivariate statistical techniques for the assessment of spatial variations in water quality of a small river. Environmental monitoring and assessment 190, 718.

Elshemy, M., Meon, G., (2016) Water Quality Assessment of Aswan High Dam Reservoir, The Nile River. Springer, pp. 105-143.

Falkowski, P.G., Hopkins, T.S., Walsh, J.J. (1980) An analysis of factors affecting oxygen depletion in the New York Bight. J. mar. Res 38, 479-506.

Fernández-Gómez, C., Bayona, J.M., Díez, S. (2012) Laboratory and field evaluation of diffusive gradient in thin films (DGT) for monitoring levels of dissolved mercury in natural river water. International journal of environmental analytical chemistry 92, 1689-1698.

Gotovtsev, A. (2010) Modification of the Streeter-Phelps system with the aim to account for the feedback between dissolved oxygen concentration and organic matter oxidation rate. Water resources 37, 245-251.

Hill, B.H., Herlihy, A.T., Kaufmann, P.R., DeCelles, S.J., Vander Borgh, M.A. (2003) Assessment of streams of the eastern United States using a periphyton index of biotic integrity. ecological indicators 2, 325-338.

Ibrahim, E.M.E., El-Liethy, M.A., Abia, A.L.K., Hemdan, B.A., Shaheen, M.N. (2019) Survival of E. coli O157: H7, Salmonella Typhimurium, HAdV2 and MNV-1 in river water under dark conditions and varying storage 
temperatures. Science of the Total Environment 648, 1297-1304.

Jahin, H.S., Abuzaid, A.S., Abdellatif, A.D. (2019) Using multivariate analysis to develop irrigation water quality index for surface water in Kafr El-Sheikh Governorate, Egypt. Environmental Technology \& Innovation.

Mehari, A.K., Gebremedhin, S., Ayele, B. (2015) Effects of bahir dar textile factory effluents on the water quality of the head waters of Blue Nile River, Ethiopia. International journal of analytical chemistry 2015.

Nel, J.L., (2008) Enhancing the conservation of freshwater biodiversity through improved freshwater conservation planning techniques. University of Cape Town.

Nyasulu, T.H. (2012) Assessment of the Quality of Water in Urban Rivers-A case study of Lilongwe River in Malawi.

O'Connor, D.J., Dobbins, W.E. (1958) The mechanics of reaeration in natural streams. Journal of the Sanitary Engineering Division 82, 1-30.

Ogundiran, M.A., Fawole, O.O. (2014) Assessment of the Impacts of Industrial Effluent Discharges on the Water Quality of Asa River, Ilorin, Nigeria. IOSR Journal of Environmental Science, Toxicology and Food Technology 8, 80-98.

Omole, D., Longe, E. (2008) An assessment of the impact of abattoir effluents on River Illo, Ota, Nigeria. Journal of Environmental Science and Technology 1, 56-64.

Orebiyi, E., Awomeso, J., Idowu, O., Martins, O., Oguntoke, O., Taiwo, A. (2010) Assessment of pollution hazards of shallow well water in Abeokuta and environs, southwest, Nigeria. American Journal of Environmental Sciences 6, 50-56.

Paul, W. (2011) Impact of industrial effluents on water quality of receiving streams in Nakawa-Ntinda, Uganda. Environment and Natural Resources, Makerere University.

Shrivastava, A., Tandon, S.A., Kumar, R. (2015) Water quality management plan for Patalganga river for drinking purpose and human health safety. International Journal of Scientific Research in Environmental Sciences 3, 71.

Streeter, H., Wright, C., Kehr, R. (1936) Measures of natural oxidation in polluted streams. III. An experimental study of atmospheric reaeration under stream-flow conditions. Sewage Works Journal, 282-316.

Taseiko, O., Spitsina, T., Milosevic, H., Radovanovic, D., Valjarevic, A. Biochemical Processes of SelfPurification Model in Small Rivers.

Van der Hoven, C., Ubomba-Jaswa, E., Van der Merwe, B., Loubser, M., Abia, A.L.K. (2017) The impact of various land uses on the microbial and physicochemical quality of surface water bodies in developing countries: Prioritisation of water resources management areas. Environmental nanotechnology, monitoring \& management 8, 280-289.

Yitayew, M., Melesse, A.M., (2011) Critical water resources issues in the Nile River Basin, Nile River Basin. Springer, pp. 401-416.

Yohannes, H., Elias, E. (2017) Contamination of rivers and water reservoirs in and around Addis Ababa city and actions to combat It. Environ Pollut Climate Change 1, 2. 